\title{
A systematic review and meta-analysis of levofloxacin and ciprofloxacin in the treatment of urinary tract infection
}

\author{
Zhisong Xue", Ying Xiang", Yutao Li, Qi Yang \\ Department of Urology and Andrology, Sichuan Academy of Medical Sciences, Sichuan Provincial People's Hospital East, Chengdu, China \\ Contributions: (I) Conception and design: Z Xue; (II) Administrative support: Y Li, Q Yang; (III) Provision of study materials or patients: Y Li; (IV) \\ Collection and assembly of data: Y Xiang; (V) Data analysis and interpretation: Z Xue; (VI) Manuscript writing: All authors; (VII) Final approval of \\ manuscript: All authors. \\ \#These authors contributed equally to this work as co-first authors. \\ Correspondence to: Qi Yang; Yutao Li. Department of Urology and Andrology, Sichuan Academy of Medical Sciences, Sichuan Provincial People's \\ Hospital East, No.585, Honghe North Road, Damian Town, Longquanyi District, Chengdu 610072, China. \\ Email: Yangqi198901@163.com; liyt0123@163.com.
}

\begin{abstract}
Background The efficacy of levofloxacin and ciprofloxacin in the treatment of urinary tract infection is not clear yet. This study perform a meta-analysis to explore the differences between the two against urinary tract infection (UTI).

Methods: A computerized literature search was conducted of the databases of PubMed, Medline, Embase, and the Cochrane Library. All the retrieved literatures were randomized comparative studies of levofloxacin and ciprofloxacin. The included studies were screened according to the standard of nanofiltration. The risk of bias was assessed with RevMan 5.3.5 software. The treatment effect index and incidence of adverse reactions index were established and compared via meta-analysis.

Results: A total of 5 studies were included, involving 2,877 patients overall. The results showed that levofloxacin was more effective than ciprofloxacin, but the difference between the 2 drugs was not statistically significant [odds ratio $(\mathrm{OR})=1.18,95 \%$ confidence interval $(\mathrm{CI}): 0.94$ to $1.46, \mathrm{P}=0.15$ ]. There was also no statistical significance in the rate of adverse reactions between the 2 drugs (OR $=0.91,95 \%$ CI: 0.78 to 1.07 , $\mathrm{P}=0.27)$.

Discussion: In the treatment of UTI, the efficacy and safety of levofloxacin and ciprofloxacin are similar statistically. If bacterial resistance is discovered after the treatment of one of the drugs, the other drug might become an alternative.
\end{abstract}

Keywords: Levofloxacin; ciprofloxacin; urinary tract infection (UTI); meta-analysis

Submitted Jul 13, 2021. Accepted for publication Aug 17, 2021.

doi: 10.21037/apm-21-2042

View this article at: https://dx.doi.org/10.21037/apm-21-2042

\section{Introduction}

Urinary tract infection (UTI) is the invasion of pathogenic bacteria (typically represented by Escherichia coli) into urothelial cells, resulting in inflammatory reactions in the urethra, causing urethral burning sensation, perineal discomfort, frequent urination, urgent urination, and other symptoms, and some patients may even have secondary systemic infection symptoms such as fever, chills, vomiting, and other reactions. Without timely intervention, the extent of bacterial erosion may greatly increase and threaten the patient's life (1). The main pathogen of this disease is Escherichia coli, although other Gramnegative and positive bacteria, and fungi are involved in mixed pathogenic infections (2). Quinolones have a wide antibacterial spectrum and can act on the gyrase that decomposes bacteria for the synthesis of DNA, thereby inhibiting the growth and reproduction of bacteria. They 
have good effect on common Gram-negative bacteria and anaerobic bacteria, and have strong drug permeability. They can rapidly increase the concentration in prostatic fluid and bladder urine and achieve a rapid bactericidal effect (3). Levofloxacin and ciprofloxacin are both common quinolones and belong to the third generation of broadspectrum antibiotics. Levofloxacin can achieve good bioavailability after oral or intravenous administration, rapidly penetrate the kidney and prostate, extensively distribute throughout the body, and it has a higher concentration in plasma than ciprofloxacin. Therefore, the clearance rate of bacteria should be higher (4). Some studies (5) showed that levofloxacin had better antibacterial effect against Gram-positive bacteria than ciprofloxacin. But others (6) have shown that the efficacy of the two is equivalent. In this study, we performed a meta-analysis on the basis of existing clinical studies to further clarify the efficacy and adverse reactions of the 2 drugs in the treatment of UTI. We present the following article in accordance with the PRISMA reporting checklist (available at https://dx.doi.org/10.21037/apm-21-2042).

\section{Methods}

\section{Literature search strategy}

We conducted a search in the following databases: PubMed, Medline, Embase and the Cochrane Library, using the search keywords: "Comparison" OR "Levofloxacin" OR "Ciprofloxacin" OR" Bacterial prostatitis", OR "Cystitis" OR "Acute pyelonephritis" OR "Urinary tract infection". The search time was restricted to literature published between 2000 and the present.

\section{Inclusion criteria}

\section{Literature types}

All included studies were of double-blind design, limited to those investigating levofloxacin and ciprofloxacin as the main drugs for the treatment of UTI, and the study types were randomized controlled studies (RCTs), with Jadad scores of more than 3 in the literature (7).

\section{Participants}

Patients (all aged $\geq 18$ years) were admitted due to frequent urination, urgency, dysuria, abdominal discomfort, hematuria, and other reasons. Clean urine midstream bacterial culture detected the prototype of infectious pathogens, and were diagnosed with one or more of acute cystitis, bacterial prostatitis, acute pyelonephritis, epididymitis, and gonococcal urethritis. Among them, acute nephritis was accompanied by an increase in body temperature of more than $38^{\circ} \mathrm{C}$, and in urinalysis, white blood cells in the urine showed positive, peripheral white blood cell count showed positive, and there was a feeling of tenderness in the chest and abdomen, accompanied by a variety of symptoms such as vomiting, dysuria, urgency, and frequent urination. The related symptoms of bacterial prostatitis were perineal and pubic pain, dysuria, lumbar discomfort, chills, and fever. In addition to general symptoms such as frequent urination, urgency, and dysuria, acute cystitis typically presented with hematuria, turbid urine, and urine odor of urinary tract irritation symptoms; a few patients had fever, and most had no symptoms of systemic infection.

\section{Intervention methods}

Participants were divided into 2 groups, the control group, levofloxacin injection and ciprofloxacin injection, respectively. The treatment methods were intravenous drip.

\section{Outcome measures}

The outcome measures of the study included (but were not limited to) 2 indicators: the treatment response rate and the incidence rate of adverse reactions of the 2 drugs.

\section{Exclusion criteria}

In this study, patients who met more than 1 of the following criteria were excluded: (I) literatures of non-RCT, case study, experience summary, cohort study, case analysis, and so on; (II) insufficient observation indicators; (III) the inclusion of drug comprehensive treatment intervention methods from other studies.

\section{Research methods}

One researcher performed data retrieval and literature collation. The Jadad score of literatures was independently calculated by 2 evaluators. A total of 4 items were scored for the included RCTs: method of random sequence generation ( $0-2$ points), hidden random sequence ( $0-2$ points), blind method (0-2 points), the number of withdrawals and reasons ( $0-1$ points). The maximum score was 7 points. A score below 3 points indicated that the quality of the RCT was low, scores of above 3 indicated that the quality was 
acceptable. If there were conflicting opinions between the evaluators regarding the same study, it was arbitrated by a third person. Data extraction was performed for the finally included literatures, including publication time, intervention measures, total number, grouping, participant characteristics, and so on. Review Manager 5.3.5 software (RevMan, Copenhagen: The Nordic Cochrane Center, The Cochrane Collaboration, 2014) was used to evaluate the bias risk of the included studies, which covered 7 aspects: (I) the generation of random sequence; (II) classification concealment; (III) double blinding of implementers and participants; (IV) blind method of outcome evaluation; (V) state of completion of the outcome evaluation; (VI) selective reporting; (VII) other bias. Then, 2 binary variables were established in the RevMan 5.3.5 software: treatment response rate and incidence rate of adverse reactions. A forest map of the analysis was obtained after entering the data.

\section{Statistical methods}

RevMan 5.3.5 software was used for statistical analysis. The $\mathrm{I}^{2}$ analysis was used to analyze the heterogeneity between literatures. An $\mathrm{I}^{2}>50 \%$ or $\mathrm{P}$ value $<0.1$ indicated that there was no heterogeneity in the results. If there was heterogeneity, subgroup analysis and sensitivity analysis were used to exclude it. The fixed effects model was used for further analysis. Sensitivity analysis was performed using the method of excluding 1 article at a time to identify the presence of heterogeneity among the remaining studies. Non-continuous binary variables were expressed using odds ratio $(\mathrm{OR})$ with a $95 \%$ confidence interval $(\mathrm{CI})$ and $\mathrm{P}<0.1$ was considered statistically significant.

\section{Results}

\section{Literature search and screening results}

A total of 84 relevant literatures (25 PubMed, 31 Medline, 16 Embase and 12 Cochrane library) were found in this search. According to the inclusion and exclusion criteria, after excluding the unqualified literatures, 5 RCTs were finally included, involving a total of 2,877 patients. Others were excluded due to low quality methodology. The 5 included RCTs are shown in Table 1.

\section{Risk assessment of bias of included literatures}

The risk assessment of the included literatures is shown in
Figure 1.

\section{Meta-analysis results}

\section{Treatment response rate}

Meta-analysis showed that there was no statistical heterogeneity in the effective rate $\left(\mathrm{I}^{2}=0 \%, \mathrm{P}=0.69\right)$, and the effective rate of levofloxacin treatment reported in 5 studies was greater than that of ciprofloxacin ( $\mathrm{OR}=1.18,95 \% \mathrm{CI}$ : 0.94 to $1.46, \mathrm{P}=0.15$ ), but the difference between the 2 drugs was not statistically significant, as shown in Figure 2.

\section{Incidence of adverse reactions}

Meta-analysis showed that there was no statistical heterogeneity in the incidence of adverse reactions $\left(\mathrm{I}^{2}=0 \%\right.$, $\mathrm{P}=0.84$ ), and there was no statistically significant difference in the adverse reaction rate after treatment of UTI between the 2 drugs reported in the 5 literatures ( $\mathrm{OR}=0.91,95 \%$ CI: 0.78 to $1.07, \mathrm{P}=0.27$ ), as shown in Figure 3.

\section{Discussion}

Levofloxacin is a third-generation of fluoroquinolone drug that is molecularly isomeric for Ofloxacin and not only inherits its broad-spectrum antibacterial characteristics, but also can enhance antibacterial activity on this basis $(13,14)$. Levofloxacin maintains biological antibacterial activity against most Gram-negative bacteria of the family Enterobacteriaceae such as (Escherichia coli, Proteus spp., and so on), Gram-positive genera (Streptococcus pneumoniae, bemolytic streptococcus, and so on), maintains sensitivity to methicillin-resistant Staphylococcus aureus, and also has high antibacterial activity against chlamydia, mycoplasma, and fungal genera such as Legionella $(15,16)$. Ciprofloxacin is also a third-generation quinolone antibacterial drug, which is characterized by strong bactericidal power, wide antibacterial spectrum, high permeability, and few adverse reactions (17).

In order to provide a better basis for evidence-based medicine, this study designed a literature survey of levofloxacin and ciprofloxacin to evaluate the efficacy and safety of both drugs in the treatment of UTI. A total of 5 articles retrieved from journal databases were included in the study, all of which compared levofloxacin with ciprofloxacin, excluding those who used or combined other drugs, and excluding articles, case studies, and reviews with incomplete outcome measures. These 5 articles were finally included in the study, all of which were in the controllable 
Table 1 Basic characteristics of included literatures

\begin{tabular}{|c|c|c|c|c|c|c|}
\hline Author & Group & Number of participants & Gender (M/F) & Age (years) & Intervention Methods & Jadad score \\
\hline $\begin{array}{l}\text { Mospan et al. } \\
\text { [2016], (8) }\end{array}$ & Observation & 350 & $189 / 161$ & $39.4 \pm 5.3$ & $\begin{array}{l}\text { Ciprofloxacin intravenous } \\
\text { injection } 500 \mathrm{mg} / \text { time, twice a } \\
\text { day, for } 10 \mathrm{~d}\end{array}$ & \\
\hline $\begin{array}{l}\text { Alqahtani et al. } \\
\text { [2013], (9) }\end{array}$ & Observation & 226 & $135 / 91$ & $48.2 \pm 1.3$ & $\begin{array}{l}\text { Ciprofloxacin intravenous } \\
\text { injection } 500 \mathrm{mg} / \text { time, twice a } \\
\text { day for } 28 \mathrm{~d}\end{array}$ & \\
\hline $\begin{array}{l}\text { Yasmeen et al. } \\
\text { [2015], (10) }\end{array}$ & Control & 70 & $35 / 35$ & $51.0 \pm 4.4$ & $\begin{array}{l}\text { Ofloxacin } 250 \mathrm{mg} / \mathrm{time} \text {, bid, for } \\
5-9 \mathrm{~d}\end{array}$ & 5 \\
\hline \multirow[t]{2}{*}{$\begin{array}{l}\text { Zhang et al. } \\
\text { [2012], (11) }\end{array}$} & Control & 209 & $106 / 103$ & $46.5 \pm 6.1$ & $\begin{array}{l}\text { Levofloxacin } 500 \text { mg/time, qd, } \\
\text { for } 30 \mathrm{~d}\end{array}$ & 5 \\
\hline & Observation & 199 & $100 / 99$ & $44.9 \pm 6.8$ & $\begin{array}{l}\text { Ciprofloxacin } 500 \mathrm{mg} / \text { time, } \\
\text { twice a day for } 30 \mathrm{~d}\end{array}$ & \\
\hline \multirow[t]{2}{*}{$\begin{array}{l}\text { Peterson et al. } \\
\text { [2008], (12) }\end{array}$} & Control & 506 & $276 / 230$ & $42.0 \pm 4.0$ & $\begin{array}{l}\text { Levofloxacin } 750 \text { mg/time, qd, } \\
\text { for } 5 \mathrm{~d}\end{array}$ & 4 \\
\hline & Observation & 587 & $335 / 252$ & $42.5 \pm 4.3$ & $\begin{array}{l}\text { Ciprofloxacin } 400 \text { mg/time, bid, } \\
\text { for } 10 \mathrm{~d}\end{array}$ & \\
\hline
\end{tabular}

range of quality, with 1 article with a Jadad score of 3 , 2 articles with a score of 4 , and 2 articles with a score of 5. Using RevMan to add outcome measures and data, the forest plot showed that the response rate of levofloxacin treatment was greater than that of ciprofloxacin, but the difference between was not statistically significant (OR $=1.18,95 \% \mathrm{CI}$ : 0.94 to $1.46, \mathrm{P}=0.15$ ), suggesting that there was no significant difference in the efficacy between the 2 drugs. In the meta-analysis by Cao et al. (18), 5 literatures were also included, with a total of 2,352 patients, and the results also showed that there was no significant difference in the efficacy of levofloxacin and ciprofloxacin in the treatment of UTI. The results of this study were consistent with the previous one. But in this meta-analysis, all 5 literatures included were published in between year 2008 and 2016, more recently than the previous study [19982012], and there were 2,877 patients involved comparing to the previous 2,352, which meant that this study gained more credits.

Although results showed that there was no significant difference in the efficacy of levofloxacin and ciprofloxacin in the treatment of UTI, but according to the administration methods included in the study, levofloxacin only needed to be administered once daily, ciprofloxacin needed to be administered twice daily, and levofloxacin treatment time was shorter than ciprofloxacin; therefore, levofloxacin had a more therapeutic advantage. In a research done by Wagenlehner et al. (19) the result showed that after receiving an oral dose of $500 \mathrm{mg}$ levofloxacin and ciprofloxacin respectively for $24 \mathrm{~h}$, the median maximum concentration of levofloxacin in plasma of the patients reached $6.1 \mathrm{mg} / \mathrm{L}$ while that of ciprofloxacin was $2.3 \mathrm{mg} / \mathrm{L}$, which recommending the dosing should be twice daily for ciprofloxacin and once daily for levofloxacin.

Levofloxacin and ciprofloxacin can quickly kill bacteria by osmotic effect and immediately increase the blood drug concentration after intravenous injection (comparing to oral medication), which can be metabolized in the urine and excreted after administration, with certain safety (20). However, some studies $(21,22)$ have pointed out that both 


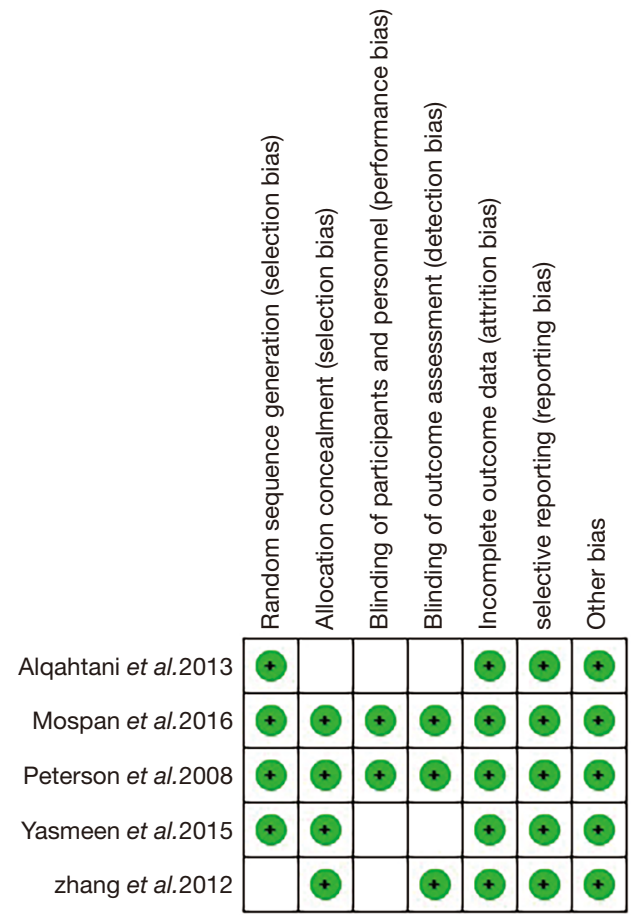

Figure 1 Summary chart of risk of bias assessment of included literatures. drugs will incur some adverse reactions during medication, and common reactions are abdominal pain, diarrhea, dizziness, headache, and insomnia, the fluoroquinolones and cephalosporins are associated with the greatest risk of microbiological collateral damage as colitis. The 5 included literatures showed that the 2 drugs had no liver and kidney damage reactions in the study, and the adverse reactions disappeared automatically after drug withdrawal, with good safety. Meta-analysis showed that there was no statistically significant difference between the adverse reaction rate of the 2 groups $(\mathrm{OR}=0.91,95 \% \mathrm{CI}: 0.78$ to $1.07, \mathrm{P}=0.27$ ), suggesting that there was little difference in the safety of the 2 drugs when used for the treatment of UTI.

In this study, all patients involved were diagnosed with complicated symptoms. The fluoroquinolones and cephalosporins have an important role in the treatment of that, which have better eradication rates and less recurrence rates over other antibiotics, but in the treatment of uncomplicated infections (with mild or moderate symptoms), the fluoroquinolones and cephalosporins were not recommended because of increasing resistance of their use (23). The best antibiotics should be chosen to cure the uncomplicated UTI in case of severe pyelonephritis symptoms, aminopenicillins

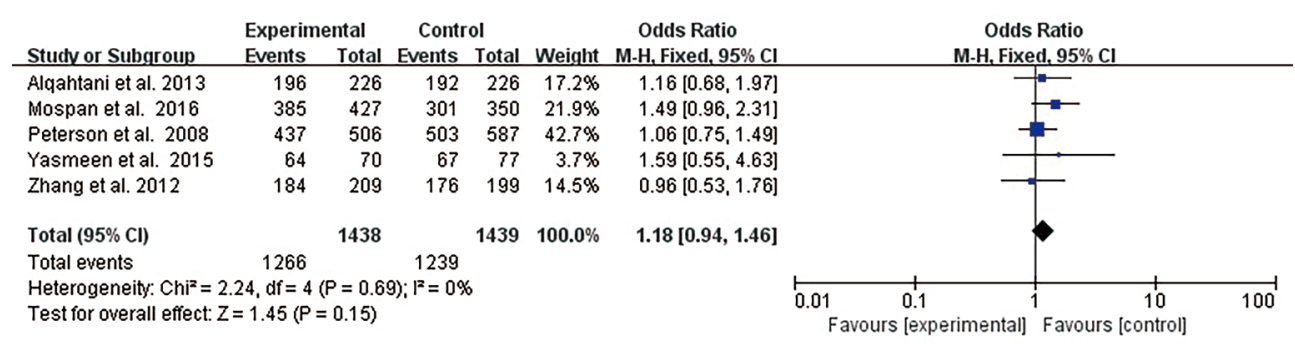

Figure 2 Effective rate of levofloxacin and ciprofloxacin in the treatment of UTI. UTI, urinary tract infection; CI, confidence interval.

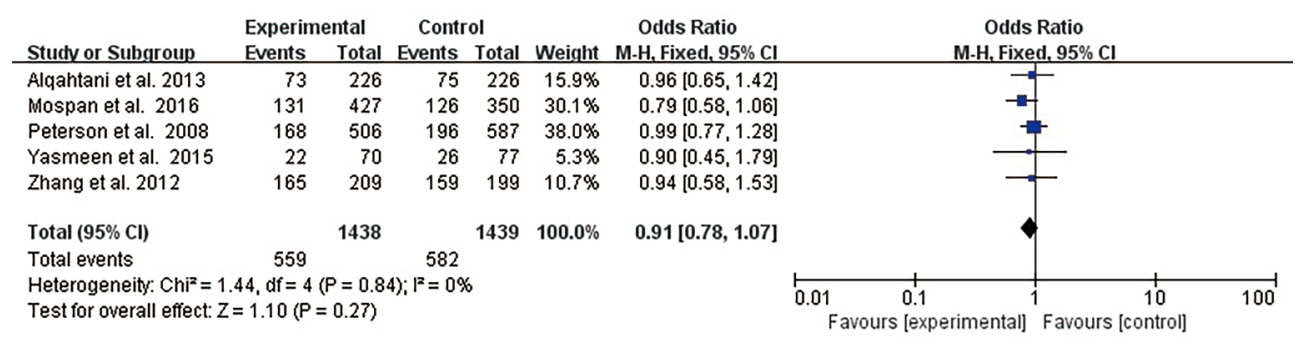

Figure 3 Effect of levofloxacin and ciprofloxacin on the incidence of adverse reactions in the treatment of UTI. UTI, urinary tract infection; CI, confidence interval. 
in combination with fosfomycin-trometamol, nitrofurantoin, nitroxoline, pivmecillinam, trimethoprim were all the suitable choices (22). Cotrimoxazole is not recommended anymore because its low efficacy and high rates of adverse events (23). The eradication rates, sensitivity and adverse events should all be considered during choosing appropriate antibiotics for UIT treatment (24).

In this study, only 5 RCTs were included, the literature search was limited to PubMed, Medline, Embase, and Cochrane Library, all literatures were not encompassed, and analysis of literature bias suggested that 5 studies still had unknown risk bias, while the dose in the intervention method was not completely uniform, which may have had a certain impact on the final results. In addition, the treatment method in the included studies was intravenous drip, orally administered drugs were not studied comprehensively, and its efficacy and safety still need to be further verified in larger sample and higher quality literatures.

\section{Conclusions}

In this meta-analysis, 5 studies (RCTs) were included, involving a total of 2,877 patients. The analysis results showed that in the treatment of UTI diseases, there was no significant difference in the efficacy and safety of levofloxacin and ciprofloxacin. If bacterial resistance was exhibited towards either of the drugs, using the other drug could be an alternative. Levofloxacin has more therapeutic advantages due to the small number of daily doses and shorter total medication time, but this was not thoroughly explored in this study.

\section{Acknowledgments}

Funding: None.

\section{Footnote}

Reporting Checklist: The authors have completed the PRISMA reporting checklist. Available at https://dx.doi. org/10.21037/apm-21-2042

Conflicts of Interest: All authors have completed the ICMJE uniform disclosure form (available at https://dx.doi. org/10.21037/apm-21-2042). The authors have no conflicts of interest to declare.

Ethical Statement: The authors are accountable for all aspects of the work in ensuring that questions related to the accuracy or integrity of any part of the work are appropriately investigated and resolved.

Open Access Statement: This is an Open Access article distributed in accordance with the Creative Commons Attribution-NonCommercial-NoDerivs 4.0 International License (CC BY-NC-ND 4.0), which permits the noncommercial replication and distribution of the article with the strict proviso that no changes or edits are made and the original work is properly cited (including links to both the formal publication through the relevant DOI and the license). See: https://creativecommons.org/licenses/by-nc-nd/4.0/.

\section{References}

1. Mabeck CE. Treatment of uncomplicated urinary tract infection in non-pregnant women. Postgrad Med J 1972;48:69-75.

2. Hsiao CY, Chen TH, Lee YC, et al. Risk factors for uroseptic shock in hospitalized patients aged over 80 years with urinary tract infection. Ann Transl Med 2020;8:477.

3. Lee JK, Lee S, Hong SK, et al. Clinical importance of the antibiotic regimen in transrectal ultrasound-guided biopsy: quinolone versus cephalosporin. BMC Urol 2016;16:51.

4. Odenholt I, Löwdin E, Cars O. Bactericidal effects of levofloxacin in comparison with those of ciprofloxacin and sparfloxacin. Clin Microbiol Infect 1998;4:264-70.

5. Colin J, Simonpoli S, Geldsetzer K, et al. Corneal penetration of levofloxacin into the human aqueous humour: a comparison with ciprofloxacin. Acta Ophthalmol Scand 2003;81:611-3.

6. Campbell JL, Fay MP, Lanning LL, et al. Effect of Delaying Treatment on Efficacy of Ciprofloxacin and Levofloxacin in the African Green Monkey Model of Pneumonic Plague. Clin Infect Dis 2020;70:S60-S65.

7. McCormick F, Cvetanovich GL, Kim JM, et al. An assessment of the quality of rotator cuff randomized controlled trials: utilizing the Jadad score and CONSORT criteria. J Shoulder Elbow Surg 2013;22:1180-5.

8. Mospan GA, Wargo KA. 5-Day versus 10-Day Course of Fluoroquinolones in Outpatient Males with a Urinary Tract Infection (UTI). J Am Board Fam Med 2016;29:654-62.

9. Alqahtani M. Comparative analysis between levofloxacin and ciprofloxacin to assess their bactericidal activity using antimicrobial susceptibility disk diffusion on isolates obtained from urine samples. Journal of the Bahrain 
Medical Society 2013;24:4-6.

10. Yasmeen B, Islam S, Islam S, et al. Prevalence of urinary tract infection, its causative agents and antibiotic pattern sensitivity: A study in Northern International Medical College Hospital, Dhaka. Northern International Medical College Journal 2015;7:105-9.

11. Zhang ZC, Jin FS, Liu DM, et al. Safety and efficacy of levofloxacin versus ciprofloxacin for the treatment of chronic bacterial prostatitis in Chinese patients. Asian J Androl 2012;14:870-4.

12. Peterson J, Kaul S, Khashab M, et al. A double-blind, randomized comparison of levofloxacin $750 \mathrm{mg}$ oncedaily for five days with ciprofloxacin 400/500 mg twicedaily for 10 days for the treatment of complicated urinary tract infections and acute pyelonephritis. Urology 2008;71:17-22.

13. Dawe RS, Ibbotson SH, Sanderson JB, et al. A randomized controlled trial (volunteer study) of sitafloxacin, enoxacin, levofloxacin and sparfloxacin phototoxicity. Br J Dermatol 2003;149:1232-41.

14. von Gottberg A, Klugman KP, Cohen C, et al. Emergence of levofloxacin-non-susceptible Streptococcus pneumoniae and treatment for multidrug-resistant tuberculosis in children in South Africa: a cohort observational surveillance study. Lancet 2008;371:1108-13.

15. Schaeffer EM. Re: Levofloxacin for BK Virus Prophylaxis following Kidney Transplantation: A Randomized Clinical Trial. J Urol 2015;194:410.

16. Barhoumi N, Labiadh L, Oturan MA, et al. Electrochemical mineralization of the antibiotic levofloxacin by electro-Fenton-pyrite process. Chemosphere 2015;141:250-7.

17. Kolpen M, Mousavi N, Sams T, et al. Reinforcement of the bactericidal effect of ciprofloxacin on Pseudomonas aeruginosa biofilm by hyperbaric oxygen treatment. Int J Antimicrob Agents 2016;47:163-7.

Cite this article as: Xue Z, Xiang Y, Li Y, Yang Q. A systematic review and meta-analysis of levofloxacin and ciprofloxacin in the treatment of urinary tract infection. Ann Palliat Med 2021;10(9):9765-9771. doi: 10.21037/apm-21-2042
18. Cao D, Shen Y, Huang Y, et al. Levofloxacin Versus Ciprofloxacin in the Treatment of Urinary Tract Infections: Evidence-Based Analysis. Front Pharmacol 2021;12:658095.

19. Wagenlehner FM, Kinzig-Schippers M, Sörgel F, et al. Concentrations in plasma, urinary excretion and bactericidal activity of levofloxacin $(500 \mathrm{mg})$ versus ciprofloxacin $(500 \mathrm{mg})$ in healthy volunteers receiving a single oral dose. Int J Antimicrob Agents 2006;28:551-9.

20. Kang G, Min SH, Kim JK, et al. Association between the Levofloxacin Plasma Concentration and Neurological Adverse Events in an Elderly Patient. J Clin Neurol 2019;15:572-4.

21. Bar N, Dubinsky V, Avraham Y, et al. 93 - Long Term Use of Ciprofloxacin and Metronidazole for Pouchitis

- The Low Rate of Adverse Events and the High Association with Antibiotic Resistance. Gastroenterology 2018;154: S-28.

22. S3-Leitlinie Strategien zur Sicherung rationale Antibiotika-Anwendung im Krankenhaus AWMFRegisternummer 092/001. Available online: www. awmf.org/leitlinien/detail/1l/092-001.html (accessed October 7, 2017).

23. Kranz J, Schmidt S, Lebert C, et al. The 2017 Update of the German Clinical Guideline on Epidemiology, Diagnostics, Therapy, Prevention, and Management of Uncomplicated Urinary Tract Infections in Adult Patients. Part II: Therapy and Prevention. Urol Int 2018;100:271-8.

24. Grabe M, Bartoletti R, Bjerklund Johansen TE, et al. Guidelines on Urological Infections. EAU Guidelines 2015. Available online: www.uroweb.org/wp-content/ uploads/19-Urological-infections_LR2.pdf (accessed October 7, 2017).

(English Language Editor: J. Jones) 